\title{
САS1ЗА: ПОЛУЧЕНИЕ И ИСПОЛЬЗОВАНИЕ ДЛЯ ОПРЕДЕЛЕНИЯ ВИРУСНОЙ РНК
}

\author{
А. С. Савинова ${ }^{1,2}$, Е. Ю. Коптев ${ }^{1}$, Е. В. Усачев ${ }^{1}$, А. П. Ткачук¹ , В. А. Гущин ${ }^{1,3 凶}$ \\ Лаборатория трансляционной медицины, \\ Национальный исследовательский центр эпидемиологии и микробиологии имени Н. Ф. Гамалеи, Москва \\ ${ }^{2}$ Кафедра биотехнологии, факультет биотехнологии и промышленной экологии, \\ Российский химико-технологический факультет имени Д. И. Менделеева, Москва \\ ${ }^{3}$ Кафедра вирусологии, биологический факультет, \\ Московский государственный университет имени М. В. Ломоносова, Москва
}

\begin{abstract}
Использование CRISPR-Cas систем для редактирования геномов организмов в последнее время стало одним из магистральных научных направлений. Между тем белки системы CAS можно применять для разработки методов молекулярной диагностики. Традиционные подходы к идентификации микроорганизмов имеют ряд недостатков: они времязатратны (культуральные методы диагностики), недостаточно чувствительны (иммунологические методы), имеют высокую себестоимость и методически сложны (ПЦР, секвенирование). Целью работы было получение функционально активного препарата белка Cas13а и изучение его поведения в различных условиях, в том числе при изменении концентрации мишени, для дальнейшего использования в диагностических целях. Была создана генетическая экспрессионная конструкция, имеющая на 5'-конце T7-промотер и ген саs 13а бактерии Leptotrichia wadei. Получены препараты функционально активной программируемой РНКазы белка Cas13а, направляющей РHК, а также РHК вируса гриппа Б (РНК-мишень). Функциональную активность РНКазы белка Саs1За определяли по появлению флуоресцентного сигнала в реакционной смеси, содержащей направляющую РНК, РНК-мишень, молекулярный PHK-маячок. Показано, что полученный препарат белка Cas13а способен специфически выявлять мишень на примере фрагментов РНК вируса гриппа Б и не обладает неспецифическими видами РНКазной активности. Данное исследование может стать основой для создания нового быстрого специфичного и чувствительного метода идентификации микроорганизмов.
\end{abstract}

Ключевые слова: ПЦР, диагностика, инфекционные заболевания, CRISPR-Cas система, Cas13a

$\square$ Для корреспонденции: Владимир Алексеевич Гущин

ул. Гамалеи, д. 18, г. Москва, 123098; wowaniada@gmail.com, vladimir.a.gushchin@gamaleya.org

Статья получена: 31.05.2018 Статья принята к печати: 07.06.2018

DOI: $10.24075 /$ vrgmu.2018.021

\section{CAS13A: PURIFICATION AND USE FOR DETECTION OF VIRAL RNA}

\author{
Savinova $\mathrm{AS}^{1,2}$, Koptev EYu ${ }^{1}$, Usachev EV ${ }^{1}$, Tkachuk AP1 ${ }^{1}$, Gushchin VA ${ }^{1,3} \otimes$ \\ ${ }^{1}$ Laboratory of Translational Biomedicine, \\ Gamaleya Federal Research Center for Epidemiology and Microbiology, Moscow \\ ${ }^{2}$ Department of Biotechnology, Faculty of Biotechnology and Industrial Ecology, \\ Mendeleev University of Chemical Technology, Moscow \\ ${ }^{3}$ Department of Virology, Faculty of Biology, \\ Lomonosov Moscow State University, Moscow
}

The use of CRIPSR-Cas systems in genome editing has recently become one of the major research areas. Meanwhile, CAS proteins can be employed to develop novel techniques for molecular diagnostics. Traditional approaches to the identification of microorganisms have a few drawbacks: they are time-consuming (microbiological methods), insufficiently sensitive (immunoassays), expensive or labor-intensive (PCR, sequencing). The aim of this work was to obtain a functionally active Cas13a protein that could be used as a diagnostic tool and study its behavior under different conditions and at various target concentrations. We constructed an expression vector with the cas13a gene of Leptotrichia wadei under the control of T7 promoter. We obtained a functionally active Cas13a RNAse with pre-programmed activity, guide RNA, and a fragment of influenza B RNA sequence serving as a target. The functional activity of Cas13 RNAse was assessed by fluorescence in the reaction mix containing guide RNA, target RNA, and a molecular RNA beacon. The obtained protein Cas13a was able to specifically recognize the target and did not exhibit any non-specific RNAse activity. This study can become a basis for developing a novel, rapid, specific and sensitive method for pathogen detection.

Keywords: PCR, diagnostics, infectious diseases, CRISPR-Cas system, Cas13a

Correspondence should be addressed: Vladimir Gushchin

Gamalei 18, Moscow, 123098; wowaniada@gmail.com, vladimir.a.gushchin@gamaleya.org

Received: 31.05.2018 Accepted: 07.06.2018

DOI: $10.24075 / \mathrm{brsmu} .2018 .021$

На протяжении многих лет человечество борется с инфекционными заболеваниями. Особо опасны инфекции, вызывающие вспышки и эпидемии [1]. Непрерывно ведется разработка новых методов диагностики, так как именно от точности диагностики зависит эффективность последующей терапии. Полимеразная цепная реакция
(ПЦР) в отличие от классических микробиологических методов идентификации микроорганизмов, основанных на культивировании с использованием дифференциальнодиагностических сред, позволяет определять микроорганизмы быстро и независимо от особенностей их жизненного цикла. Активному внедрению ПЦР 
способствует развитие методов секвенирования и легкий доступ к последовательностям геномов в открытых базах данных [2].

Тем не менее потребность в разработке новых методов молекулярной диагностики по-прежнему остается. Расширение спектра использования ПЦР ограничивают высокая стоимость оборудования, необходимость создания специализированных лабораторных помещений и отсутствие персонала, имеющего высокую квалификацию. В качестве альтернативы ПЦР предлагаются различные варианты мобильных биосенсоров использующих комбинацию физических и биохимических подходов [3-5], а также подходы, совсем не требующие сложных приборов $[6,7]$ Наиболее перспективной, по нашему мнению, разработкой, сочетающей высокую специфичность и чувствительность на уровне единичных молекул, является SHERLOCK (specific high-sensitivity enzymatic reporter unlocking) [8, 9].

SHERLOCK основан на комбинировании изотермической амплификации нуклеиновых кислот исследуемого образца с работой Cas13а и позволяет детектировать как молекулы ДНК, так и РНК. Изотермическая амплификация используется для накопления мишени, а Cas13а выполняет функцию специфического сенсора, позволяющего точно распознавать заданные мишени и различать даже единичные нуклеотидные замены [9].

Активация нуклеазной активности Cas13а начинается со связывания направляющей PHK (crPHK) с Cas13a, после чего в структуре белка происходят значительные конформационные изменения, цель которых формирование канала для дальнейшего связывания PHK-мишени [10]. Когда Cas13a встречается с PHKмишенью, происходит образование дуплекса сrPHК:PHКмишень в положительно заряженном канале «NUC lobe». PHK-мишень служит своеобразным активатором, так как образование дуплекса катализирует сближение каталитических доменов с последующим формированием сайта расщепления РНК. Использование зонда РНК позволяет визуализировать процесс работы Cas13 по накоплению флуоресцентного сигнала.

Целью публикуемой работы было получение функционально активного препарата Cas13a, а также изучение его активности в различных условиях, в том числе при изменении концентраций мишени. В качестве мишени был использован фрагмент РНК вируса гриппа Б.

\section{МАТЕРИАЛЫ И МЕТОДЫ}

\section{Получение рекомбинантного белка LwCas13a}

Для получения препарата рекомбинантного белка Cas13а Leptotrichia wadei (LwCas13a) ген с оптимизированным кодоновым составом, синтезированный de novo (Евроген, Россия), был встроен в генетический экспрессионный вектор pET42b(+) под контролем lacT7 промотора. Экспрессию гена проводили в штамме Escherichia coli BL21(DE3)pLysS, со стороны C-конца Cas13а имел октогистидиновую метку. Индукцию осуществляли с использованием изопропил- $\beta$-D-1-тиогалактопиранозида (ИПТГ). Замороженную биомассу ресуспендировали в лизирующем буфере (20 мМ Трис- $\mathrm{HCl}$ рH 8,8; 500 мМ $\mathrm{NaCl} ; 5$ мM $\beta$-меркаптоэтанола) и разрушали под воздействием циклических ультразвуковых импульсов. Лизат осветляли центрифугированием при $15000 \mathrm{~g}$ в течение 20 мин, супернатант использовали для проведения аффинной хроматографии на автоматизированной системе среднего давления NGC Discover'm 10 (BioRad, CШA), использовали колонку HisPrep FF 16/10 (GE, Германия) объёмом 20 мл, заряженную ионами $\mathrm{Ni}^{2+}$. Для освобождения от неспецифически связавшихся примесей в буферные растворы для хроматографии добавляли Triton X-100 до конечной концентрации 0,1\%. Элюцию белка осуществляли в линейном градиенте имидазола до конечной концентрации 0,5 М. После хроматографии, фракции, содержащие Cas13a, объединяли и диализировали против буфера хранения (20 мМ Трис-HCl pH 8,0; 200 мМ NaCl; 0,1 мМ ЭДТА). Концентрацию белка измеряли спектрофотометрически с помощью прибора Implen NanoPhotometer (IMPLEN, Германия) при длине волны 280 нм. Расчет концентрации проводили с учетом коэффициента экстинкции $[11,12]$.

\section{Получение РНК-мишени и направляющей РНК}

Для получения направляющей РНК и РНК-мишени использовали метод ПЦР с последующей транскрипцией ПЦР-продукта с помощью qPCRmix-HS SYBR (Евроген, Россия) по протоколам производителя. Для получения направляющей РНК использовали искусственно синтезированные олигонуклеотиды-праймеры, обладающие участком самокомплементарности. Для получения PHKмишени амплифицировали фрагмент плазмиды, несущей последовательность генома вируса гриппа Б и фага MS2. Транскрипцию in vitro с полученных ПЦР-продуктов проводили с использованием MEGAscript ${ }^{\circledR}$ T7 Kit (Thermo Fisher Scientific, США).

\section{Определение сторонних видов нуклеазных активностей LwCas13a}

В качестве аналитического сигнала для проверки сторонних видов нуклеазных активностей LwCas13a использовали флууоресценцию, появляющуюся при расщеплении репортерной молекулы PHK RNAseAlert v2 Substrate (Thermo fisher scientific, США). Репортерная молекула РНК представляет собой олигонуклеотидмаячок с флуоресцентным красителем на 5'-конце и его гасителем на 3'-конце. При расщеплении молекулы краситель отделяется от гасителя и испускает квант света в зеленом спектре (длина волны 520 нм). Препарат LwCas13а в конечной концентрации 450 нM инкубировали в реакционной смеси состоящей из нуклеазного бусера и репортерной PHK (40 мМ Tрис-HCl pH 7,3; 60 мM NaCl; 6 мM $\mathrm{MgCl}_{2} ; 125$ нM RNAseAlert v2 Substrate) в течение 2 ч при $37^{\circ} \mathrm{C}$, изменение фрлюоресценции регистрировали в реальном времени с использованием амплификатора QuantStudio 5 Real-Time PCR System (Applied Biosystems, США). В качестве положительного контроля использовали РНКазу А (Thermo fisher scientific, США), в качестве отрицательного - чистую репортерную РНК.

\section{Проверка эндонуклеазной активности белка LwCas13a}

Реакционная смесь для определения эндонуклеазной активности LwCas13a состояла из нуклеазного буфера (40 мM Трис-HCl pH 7,3; 60 мM NaCl; 6 мM MgCl$_{2}$ ), 450 мM LwCas13a, 22,5 нM crPHK, 125 мM RNAseAlert v2 Substrate, 2 мкл RiboLock RNase Inhibitor, 100 нг PHК вируса табачной мозаики (в качестве фона) и различных концентраций PHK-мишени. Детекцию флуоресцентного сигнала осуществляли в реальном времени в течение 2 ч при $37^{\circ} \mathrm{C}$ 
с использованием амплификатора QuantStudio 5 RealTime PCR System (Applied Biosystems, CШA).

\section{РЕЗУЛЬТАТЫ ИССЛЕДОВАНИЯ}

\section{Получение препарата рекомбинантного LwCas13a}

Препарат рекомбинантного белка LwCas13a получали с применением аффинной хроматографии. Анализ фракций в системе денатурирующего электрофореза белков показал, что во время индукции клетки E. coli продуцируют растворимый белок с молекулярной массой, сопоставимой с расчетной для LwCas13a (139,8 кДа) (рис. 1).

\section{Оптимизация концентрации репортерной РНК (RNAseAlert) в реакционной смеси}

Для получения оптимальных значений флуоресценции провели серию модельных экспериментов с использованием РНКазы А (рис. 2). Для дальнейших экспериментов была выбрана концентрация субстрата 125 нМ, так как именно при этом значении обеспечивался максимальный динамический диапазон в 100000 условных единиц флуоресценции.

\section{Проверка сторонних видов РНКазной активности препарата LwCas13a}

Проверку препарата белка LwCas13a на наличие неспецифических видов РНКазной активности проводили с помощью инкубации белка LwCas13а с флуоресцентным субстратом RNAseAlert v2 Substrate в отсутствии сrPHK и PHK-мишени в течение 2 ч, изменения флуоресцентного сигнала при этом не наблюдалось. В качестве положительного контроля инкубировали флуоресцентный субстрат с РНКазой А, в качестве отрицательного контроля - с препаратом репортерной PHК (рис.3). Можно заключить, что по разработанной методике был получен препарат белка LwCas13a, не проявляющий неспецифических видов РНКазной активности, что позволило перейти к изучению свойств программируемой РНКазы.

\section{Определение чувствительности метода детекции на основе препарата белка LwCas13a на примере вируса гриппа Б}

Определение чувствительности системы детекции с использованием белка LwCas13а проводили в модельных экспериментах с вирусной РНК-мишенью фрагмента генома вируса гриппа Б. В ходе экспериментов с препаратами LwCas13a нижним детектируемым порогом чувствительности оказалось множество $10^{7}$ молекул вирусных РНК-мишеней (рис. 4 и рис. 5).

\section{ОБСУЖДЕНИЕ РЕЗУЛЬТАТОВ}

Использование LwCas13a для детекции патогенных микроорганизмов открывает большие перспективы. Методика, адаптированная в 2017 г. [7, 9] и названная SHERLOCK, основана на сочетании распознавания белком Cas13а молекул PHK, полученных в результате предварительной амплификации с использованием рекомбиназной полимеразной амплификации (RPA) и Т7-транскрипции. Все реакции проходят в одной смеси. Используя такой подход, исследователи создали платформу для диагностики вируса Зика, обладающую аттомолярной чувствительностью и специфичностью, не уступающую количественной ПЦР (рвПЦР) и цифровой капельной ПЦР. В первую очередь ученые исследовали ортологи белка Cas13а, для получения надежного флуоресцентного сигнала при активации РНКазной активности белка Cas13а. Cas13a Leptotrichia wadei, способен детектировать до 50 пМ PHК-мишени [7]. Именно этот фермент был взят за основу при разработке платформы SHERLOCK. Несмотря на высокую чувствительность, авторы исследовали возможность совмещения Cas13а-детектирования с различными вариантами изотермической амплификации,

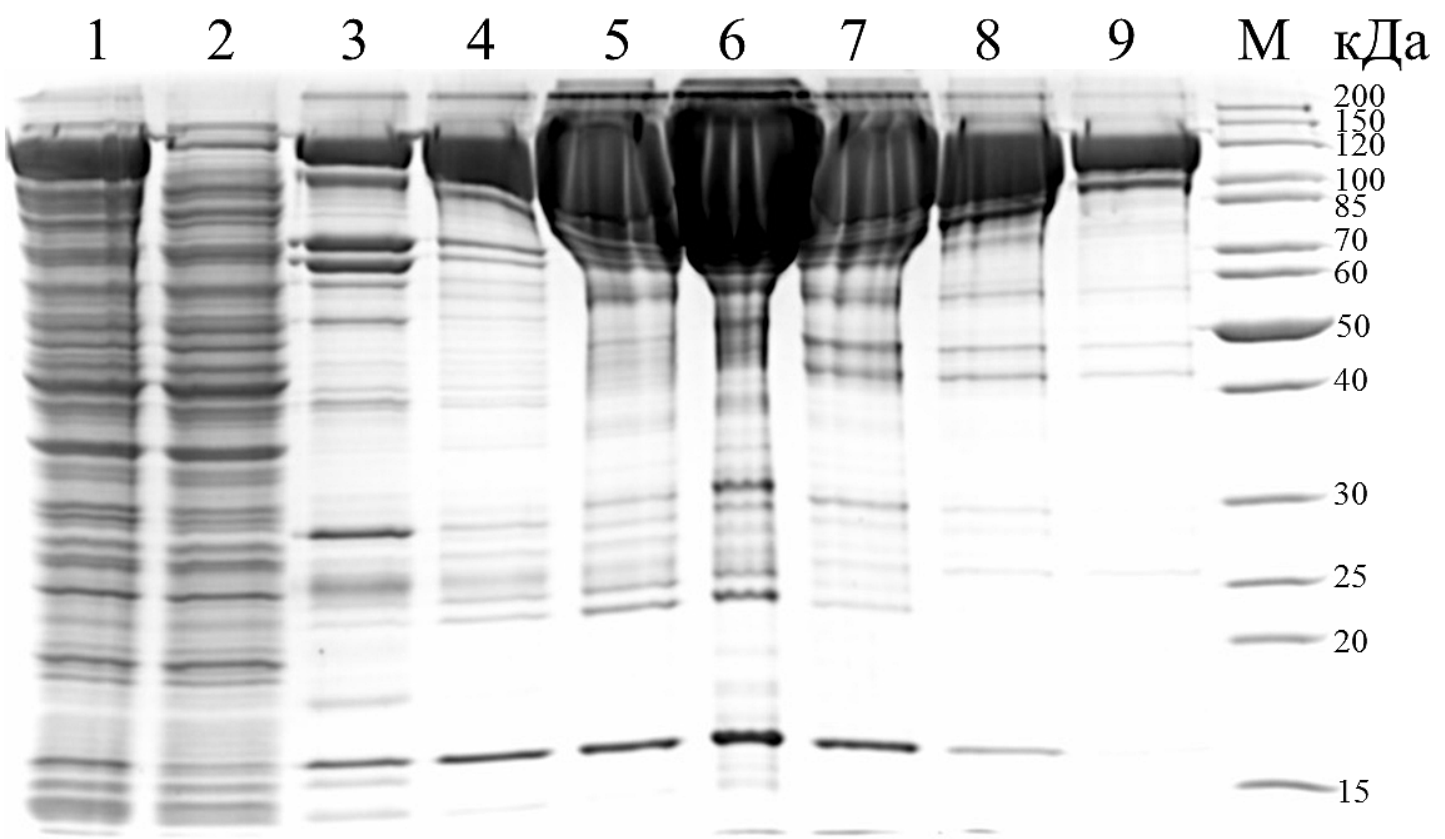

Рис. 1. Получение препарата рекомбинантного белка LwCas13a. Анализ фракций после аффинной хроматограсии в системе денатурирующего электрофореза белков: 1 - клеточный лизат до хроматографии; 2 - белки не связавшиеся с хроматографическим носителем; 3-9 - фракции элюата; М - маркер молекулярного веса 


\section{ORIGINAL RESEARCH I MICROBIOLOGY}

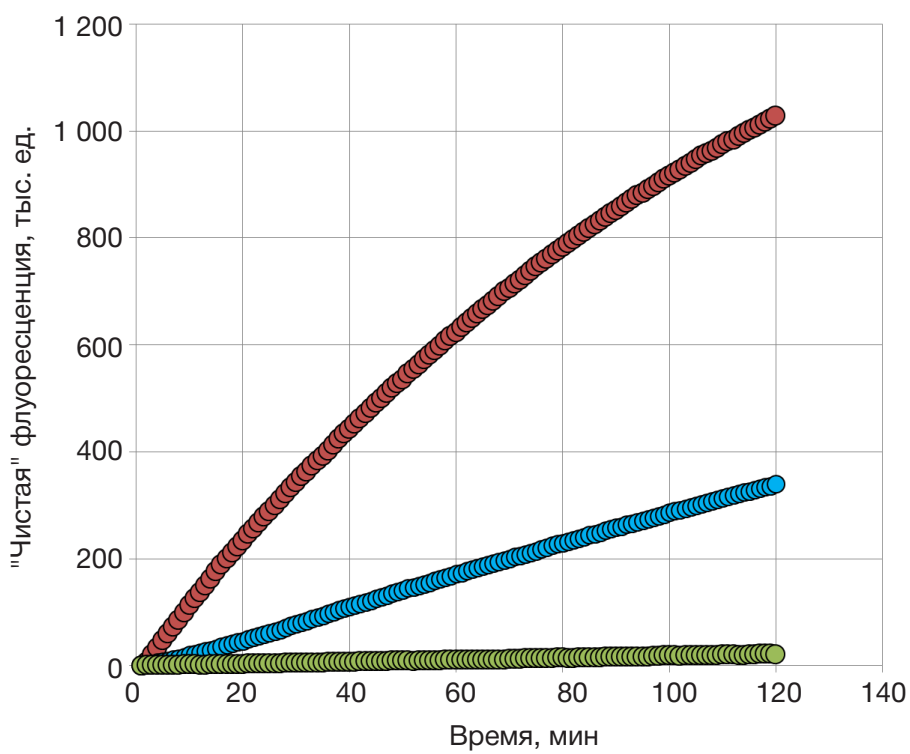

Концентрация

RNAseAlert 125 HM

- Концентрация RNAseAlert 55,7 нM

o- Концентрация

RNAseAlert 22,3 HM

Рис. 2. Кинетика изменения сигнала флуоресценции при инкубировании различных концентраций RNAseAlert c PHКазой A

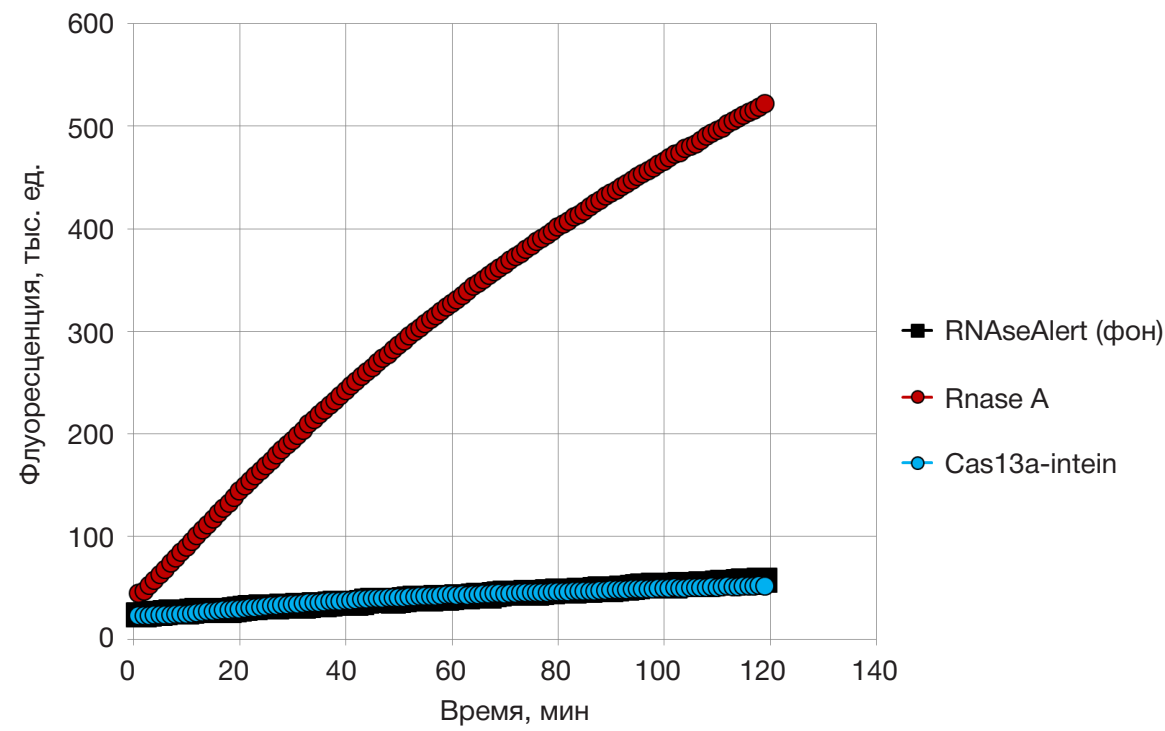

Рис. 3. Кинетика изменения сигнала флуоресценции при исследовании наличия сторонних PHКазных активностей препарата LwCas13а

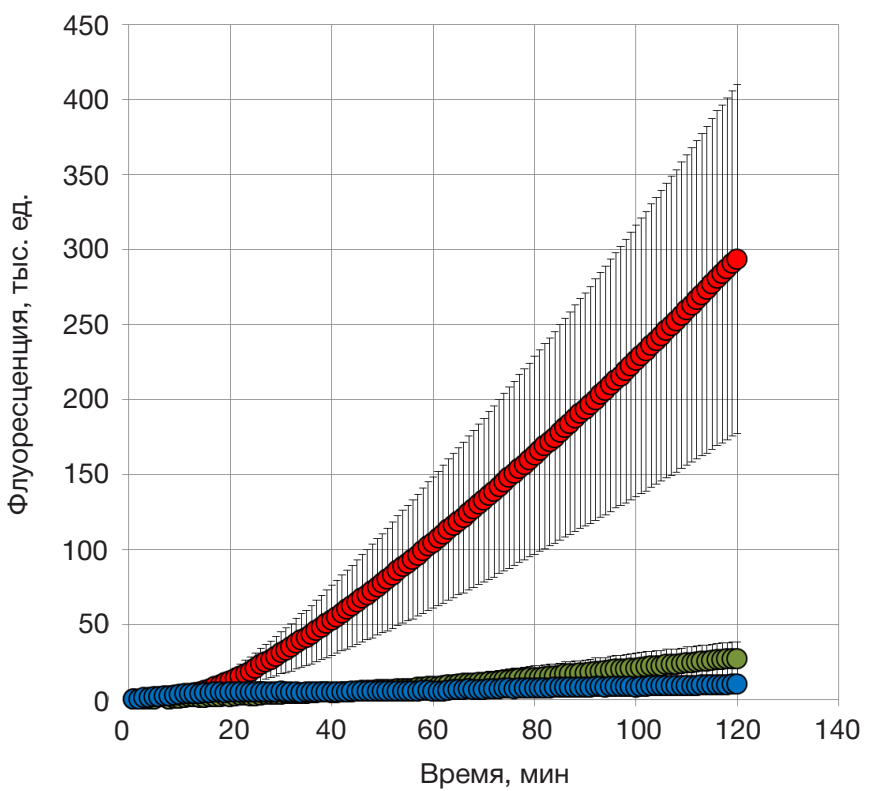

- Cas13a + мишень $10^{7}$ мол.

o- Cas $13 a+$ мишень $2 \times 10^{5}$ мол

- - Cas13a + мишень $10^{2}$ мол.

Рис. 4. Кинетика изменения сигнала флуоресценции при добавлении различных концентраций РНК-мишени 


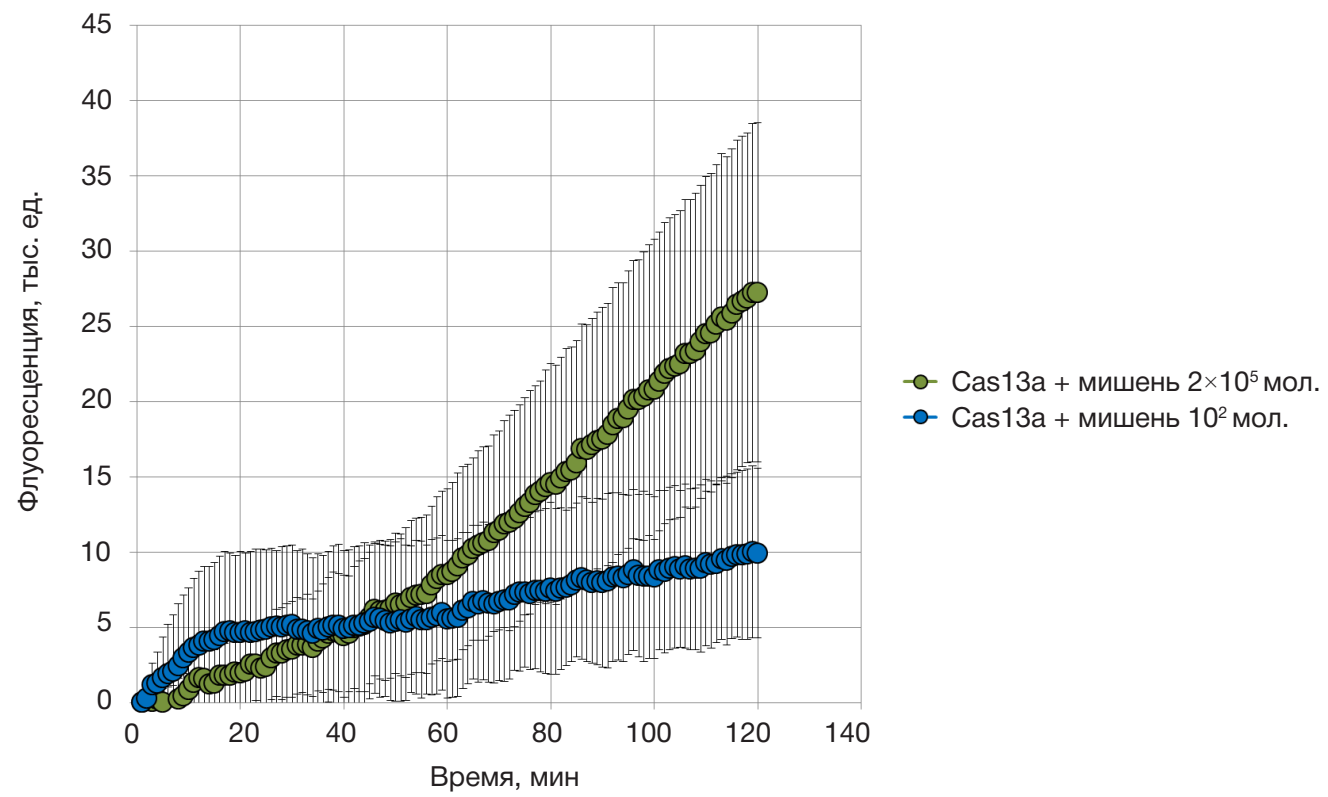

Рис. 5. Кинетика изменения сигнала флуоресценции при малых концентрациях РНК-мишени гриппа Б

и пришли к выводу, что RPA в сочетании с транскрипцией и РНКазной активностью белка Cas13а способна увеличить чувствительность метода. Было показано, что созданная платформа SHERLOCK способна различать PHK-мишени, отличающиеся друг от друга на один нуклеотид, при очень маленьких их концентрациях в растворе, а также может быть применима для портативного использования [7, 9].

В данной работе мы синтезировали вариант белка LwCas13a с оптимизированным кодоновым составом. В отличие от ранее описанного [7, 9], последовательность данного белка была изменена для его высокоэффективной продукции в клетках E. coli. Полученные штаммыпродуценты позволяют получать до 10 мг с 1 л культуры (рис. 1). Нами была разработана методика очистки Cas13a и проведены тесты, показывающие, что программируемая РНКаза не проявляет неспецифической РНКазной активности. Отсутствие последней свидетельствует о высокой чистоте полученного препарата. Далее мы отработали тесты по специфической in vitro детекции РНКазной активности белка Cas13а на основе фрагментов РНК вируса гриппа Б. Было показано, что без предварительной наработки мишени с использованием ранее описанных методик RPA и транскрипции с T7- полимеразой $[7,9]$ чувствительность детекции составляет $10^{7}$ молекул.

ВЫВОДЫ

В рамках данной работы был синтезирован вариант белка Cas13a Leptotrichia wadei с оптимизированным кодоновым составом, позволяющий получать функционально активный препарат программируемой РНКазы в клетках E. coli. Показано, что полученный препарат белка обладает специфической РНКазной активностью, не проявляет сторонних видов нуклеазной активности и способен специфически определять мишень на примере фрагментов PHК вируса гриппа Б. Дальнейшие исследования будут направлены на совершенствование метода: повышение его чувствительности, изучение специфичности программируемой РНКазы и повышение мультиплексности. Кроме того, будет предпринята попытка по созданию на основе Cas13а полевых диагностикумов. Применение полевых методов диагностики может существенно упростить контроль инфекционных агентов в переносчиках и окружающей среде, позволяя предотвратить попадание возбудителей инфекций в человеческую популяцию [13-15].

\section{Литература}

1. Makarov V, Khromov AV, Gushchin VA, Tkachuk AP. Emergence Of New Infections In The 21st Century And Identification Of Pathogens Using Next Generation Sequencing. Bulletin of Russian State Medical University. 2017; 01: 5-25.

2. Fournier PE, Dubourg G, Raoult D. Clinical detection and characterization of bacterial pathogens in the genomics era. Genome medicine. 2014; 6 (11): 114.

3. Karadeema RJ, Stancescu M, Steidl TP, Bertot SC, Kolpashchikov DM. The owl sensor: a 'fragile' DNA nanostructure for the analysis of single nucleotide variations. Nanoscale. 2018; 10: 10116-22.

4. Durmanov NN, Guliev RR, Eremenko AV, Boginskaya IA, Ryzhikov IA, Trifonova EA, et al. Non-labeled selective virus detection with novel SERS-active porous silver nanofilms

fabricated by Electron Beam Physical Vapor Deposition. Sensors Actuators B: Chemical. 2018; 257: 37-47.

5. Pachauri V, Ingebrandt S. Biologically sensitive field-effect transistors: from ISFETs to NanoFETs. Essays Biochemistry. 2016; 60 (1): 81-90.

6. Stein V, Alexandrov K. Synthetic protein switches: Design principles and applications. Trends in Biotechnology. 2015; 33 (2): 101-10.

7. Gootenberg JS, Abudayyeh OO, Kellner MJ, Joung J, Collins JJ, Zhang F. Multiplexed and portable nucleic acid detection platform with Cas13, Cas12a, and Csm6. Science. 2018; 360 (6387): 439-44.

8. East-Seletsky A, O'Connell MR, Knight SC, Burstein D, Cate JHD, Tjian R, et al. Two distinct RNase activities of CRISPR-C2c2 
enable guide-RNA processing and RNA detection. Nature. 2016; 538 (7624): 270-73

9. Gootenberg JS, Abudayyeh OO, Lee JW, Essletzbichler P, Dy AJ, Joung J, et al. Nucleic acid detection with CRISPR-Cas13a/ C2c2. Science. 2017; 356 (6336): 435-42.

10. Liu L, Li X, Wang J, Wang M, Chen P, Yin M, et al. Two Distant Catalytic Sites Are Responsible for C2c2 RNase Activities. Cell. 2017; 168 (1-2): 121-34.

11. Gill SC, von Hippel PH. Calculation of protein extinction coefficients from amino acid sequence data. Analitical Biochemistry. 1989; 182 (2): 319-26.

12. Pace CN, Vajdos F, Fee L, Grimsley G, Gray T. How to measure and predict the molar absorption coefficient of a protein. Protein Science. 1995; 4 (11): 2411-23.

13. Li CX, Shi M, Tian JH, Lin XD, Kang YJ, Chen LJ, et al. Unprecedented genomic diversity of RNA viruses in arthropods reveals the ancestry of negative-sense RNA viruses. Elife. 2015; 4: 1-26.

14. Shi M, Lin XD, Tian JH, Chen LJ, Chen X, Li CX, et al. Redefining the invertebrate RNA virosphere. Nature. 2016; 540 (7634): 53943.

15. Gao GF. Commentary From " A " IV to " Z " IKV: Attacks from Emerging and Re-emerging Pathogens. Cell. 2018; 172 (6): 1157-59.

\section{References}

1. Makarov WV, Khromov AV, Gushchin VA, Tkachuk AP. Emergence Of New Infections In The 21st Century And Identification Of Pathogens Using Next Generation Sequencing. Bulletin of Russian State Medical University. 2017; 01: 5-25.

2. Fournier PE, Dubourg G, Raoult D. Clinical detection and characterization of bacterial pathogens in the genomics era. Genome medicine. 2014; 6 (11): 114.

3. Karadeema RJ, Stancescu M, Steidl TP, Bertot SC Kolpashchikov DM. The owl sensor: a 'fragile' DNA nanostructure for the analysis of single nucleotide variations. Nanoscale. 2018; 10: 10116-22.

4. Durmanov NN, Guliev RR, Eremenko AV, Boginskaya IA, Ryzhikov IA, Trifonova EA, et al. Non-labeled selective virus detection with novel SERS-active porous silver nanofilms fabricated by Electron Beam Physical Vapor Deposition. Sensors Actuators B: Chemical. 2018; 257: 37-47.

5. Pachauri V, Ingebrandt S. Biologically sensitive field-effect transistors: from ISFETs to NanoFETs. Essays Biochemistry. 2016; 60 (1): 81-90.

6. Stein V, Alexandrov K. Synthetic protein switches: Design principles and applications. Trends in Biotechnology. 2015; 33 (2): 101-10.

7. Gootenberg JS, Abudayyeh OO, Kellner MJ, Joung J, Collins JJ, Zhang F. Multiplexed and portable nucleic acid detection platform with Cas13, Cas12a, and Csm6. Science. 2018; 360 (6387): 439-44.

8. East-Seletsky A, O'Connell MR, Knight SC, Burstein D, Cate JHD, Tjian R, et al. Two distinct RNase activities of CRISPRC2c2 enable guide-RNA processing and RNA detection. Nature. 2016; 538 (7624): 270-73.

9. Gootenberg JS, Abudayyeh OO, Lee JW, Essletzbichler P, Dy AJ, Joung J, et al. Nucleic acid detection with CRISPR-Cas13a/ C2c2. Science. 2017; 356 (6336): 435-42.

10. Liu L, Li X, Wang J, Wang M, Chen P, Yin M, et al. Two Distant Catalytic Sites Are Responsible for C2c2 RNase Activities. Cell. 2017; 168 (1-2): 121-34.

11. Gill SC, von Hippel PH. Calculation of protein extinction coefficients from amino acid sequence data. Analitical Biochemistry. 1989; 182 (2): 319-26.

12. Pace CN, Vajdos F, Fee L, Grimsley G, Gray T. How to measure and predict the molar absorption coefficient of a protein. Protein Science. 1995; 4 (11): 2411-23.

13. Li CX, Shi M, Tian JH, Lin XD, Kang YJ, Chen LJ, et al. Unprecedented genomic diversity of RNA viruses in arthropods reveals the ancestry of negative-sense RNA viruses. Elife. 2015; 4: 1-26.

14. Shi M, Lin XD, Tian JH, Chen LJ, Chen X, Li CX, et al. Redefining the invertebrate RNA virosphere. Nature. 2016; 540 (7634): 53943 .

15. Gao GF. Commentary From " A " IV to " $Z$ " IKV: Attacks from Emerging and Re-emerging Pathogens. Cell. 2018; 172 (6): 1157-59. 